\title{
VOLUMETRIC DEFORMABILITY AND WATER MASS EXCHANGE OF BENTONITE AGGREGATES
}

Navarro, V. ${ }^{1}$, Asensio, L. ${ }^{1}$, Yustres, Á. ${ }^{1}$, Pintado, X. ${ }^{2}$, and Alonso, J. ${ }^{1}$

1. Geoenvironmental Group, Civil Engineering Department, University of Castilla-La Mancha, Spain

2. B+Tech Oy, Helsinki, Finland

Authors' postprint version of the paper published in Engineering Geology:

Engineering Geology 166 (2013) 152-159, doi:10.1016/j.enggeo.2013.09.011

\begin{abstract}
A constitutive model of the volumetric behaviour of bentonite aggregates is proposed. The model is based on a state function to define the inter-aggregate (microstructural) void ratio and on a mass transfer function to calculate the mass exchange between macrostructural and microstructural water. Although both functions have been used previously for clay soils, their application beyond the range for which they were derived is proposed. To evaluate whether this extrapolation is valid, data on the swelling of individual bentonite aggregates are analysed. This novel aspect of this study is significant because it is not common to analyse microstructural data directly without introducing any hypothesis about the behaviour of the macrostructure. Despite the lack of a more intensive validation, which will be conducted when more experimental data become available, the results obtained have been satisfactory.
\end{abstract}

\section{Keywords}

Bentonite aggregates; double porosity model; microstructure; water mass exchange 


\section{Introduction}

Expansive bentonite is a clay soil with significant engineering applications, especially in the construction of municipal and industrial waste landfill liners (US EPA, 1993) and barriers for the storage of spent nuclear fuel (see, for instance, Chegbeleh et al., 2008; Cui et al., 2002; Gens et al., 1998; Pusch, 1992; Pusch and Weston, 2012; Yong, 1999b). Important contributions to the modelling of the bentonite behaviour have been made. Particularly relevant are the advancements presented at important conferences, such as the 3rd International Conference on Expansive Soils held in 1973 in Haifa (Israel), the International Symposium on Soil Structure, held the same year in Stockholm (Sweden), and the workshop 'Microstructural modelling of natural and artificially prepared clay soils with special emphasis on the use of clays for waste isolation', which was held in 1998 in Lund (Sweden) (Issues 1 and 2 in volume 54 of Engineering Geology; Pusch, 1999; Yong, 1999a). At this last workshop, Alonso et al. (1999) presented the 'Barcelona Expansive Model' (BExM), which was based on the conceptual approach proposed by Gens and Alonso (1992). The model is based on the idealisation of the bentonite structure as having two structural levels, a macrostructure and a microstructure. BExM has proven to be a powerful tool for characterising the behaviour of bentonites (see, for instance, Lloret et al., 2003), thereby demonstrating the power of conceptual models based on double porosity approaches.

It is therefore of great interest that progress is made in the macroscopic characterisation of the microstructure behaviour of bentonite. This is not a simple task because it is not easy to obtain isolated information about microstructure behaviour, i.e., information about the microstructure that is not coupled to macrostructural processes. Data on bentonite aggregate deformability available from Montes-H (2005), Montes-H et al. (2003a; 2003b; 2005a; 2005b), Farulla et al. (2010), and Romero et al. (2011) are consequently very useful. In those studies, environmental scanning electron microscopy (ESEM) was combined with digital image analysis to identify individual bentonite aggregates, characterising their area variation as a function of environmental relative humidity. 
ESEM images are sensitive to working conditions. Particularly, when monitoring microstructural changes along drying and wetting paths with varying gas pressures (as done by Montes-H and co-workers), it is important to maintain a constant working distance (Romero and Simms, 2008). However, if the ESEM images are obtained carefully, they provide information that is valuable for understanding the behaviour of soil microstructure (Romero and Simms, 2008). In the following sections, a constitutive model for the volumetric behaviour of bentonite aggregates is proposed, and the experimental results obtained by Montes-H (2005) and Montes-H et al. (2003a; 2003b) are used to assess its range of applicability and limitations.

\section{Aggregate concept and aggregate deformability}

A bimodal pore size distribution is evidenced in compacted bentonite from mercury intrusion porosimetry (MIP) tests (Alonso et al., 1987; Collins, 1984; Collins and McGown, 1974; Pusch, 1982) (Fig. 1). The predominant smaller pore sizes are in the vicinity of $10 \mathrm{~nm}$ and correspond to pores inside clay aggregates. The predominant larger pore sizes of the MIP-bimodal distribution depend on the dry density, which depends of the compaction load (e.g., $10 \mu \mathrm{m}$ for dry density $\rho_{\mathrm{d}}=1.8 \mathrm{~g} / \mathrm{cm}^{3}$ and $40 \mu \mathrm{m}$ for dry density $\rho_{\mathrm{d}}=1.5 \mathrm{~g} / \mathrm{cm}^{3}$ ) (Lloret et al., 2003; Romero, 1999; Romero et al., 1999). Despite the pore size distribution being a continuum, a boundary between the two pore families, that is, between the intra-aggregate porosity and inter-aggregate porosity, has been identified at approximately 100 nm by different authors (Romero and Simms, 2008; Lloret et al., 2003; Romero, 1999). Pores smaller than this size do not appear to be affected by the level of the compaction load (Montes-Hernandez et al., 2006; Lloret et al., 2003; Romero, 1999). As other authors have done (see, for example, Romero and Simms, 2008; Lloret et al., 2003; Pusch and Moreno, 2001; Romero, 1999; Romero et al., 1999; Pusch, 1982) and as proposed by Gens and Alonso (1992), the bimodal pore size distribution of the soil is idealised in this study using a double porosity model.

Macroporosity is associated with the inter-aggregate pores. The soil deformation is due to the rearrangement of the granular-like skeleton formed by the aggregates. Therefore, its behaviour may be described by 'conventional' models for the 
unsaturated soil mechanics (Lloret et al., 2003), as the Barcelona Basic Model (Alonso et al., 1990).

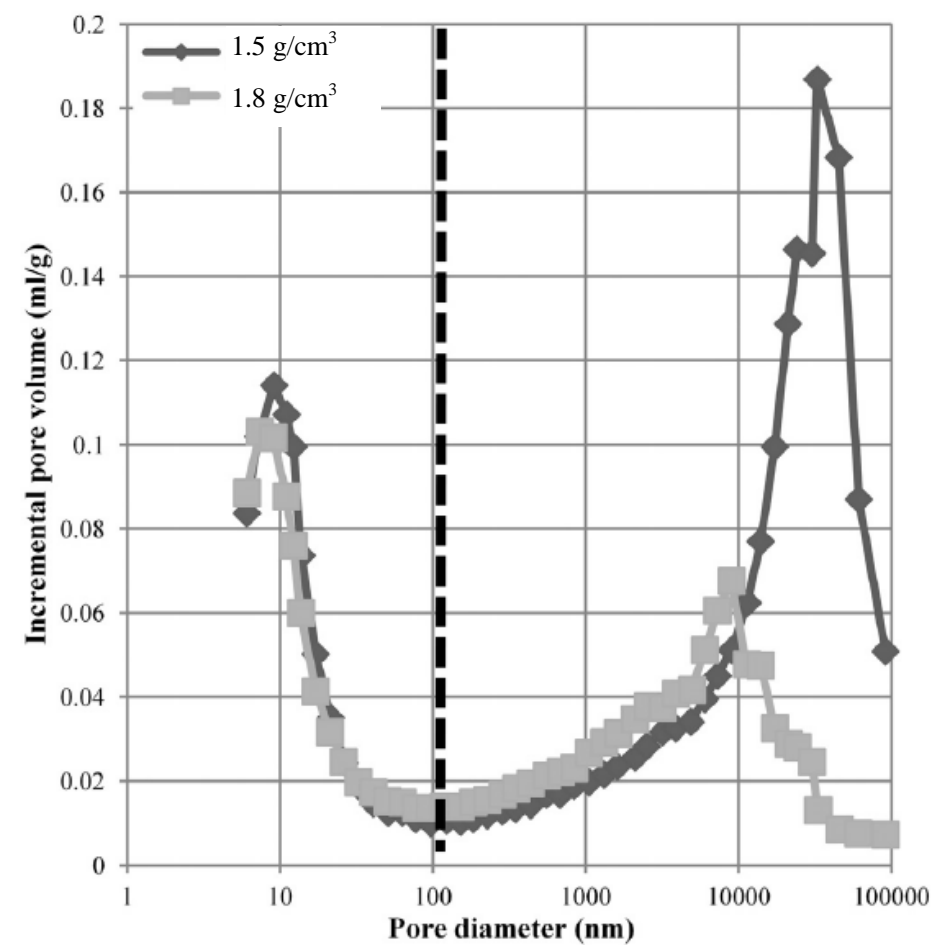

Figure 1. Distribution of incremental pore volume for two compacted bentonite samples at different dry densities. Adapted from Lloret et al. (2003)

The microstructural level is associated with intra-aggregate porosity due to intersheet voids as well as interstack voids. One sheet is 'the smallest building of clay'. A montmorillonite sheet has a 2:1 structure and is formed by an octahedral aluminium oxide layer sandwiched between two tetrahedral silicon oxide layers (see van Olphen, 1977). The sheets are approximately $1 \mathrm{~nm}$ thick and are typically between 50 and $300 \mathrm{~nm}$ long in the other directions (Neretnieks et al., 2009). A number of sheets held together mostly face to face is known as a 'stack' (Figs. 2a and b). When sodium is the dominant counterion, the stacks consist of one sheet or a few sheets (Cadene et al., 2005). When calcium dominates, the stacks typically consist of 5 to 15 sheets or more (Pusch and Yong, 2006). Aggregates are formed by the agglomeration of stacks that are held together more loosely than the sheets in stacks.

As Fig. 2c shows, the stacks are not necessarily arranged in a parallel mode inside the aggregates. In addition, heterogeneities can be produced in the interior of the 
stacks, as shown in Figs. 2a and b. Therefore, the interior of the aggregates has a complex topology that is difficult to characterise. It is reasonable to expect two hierarchical levels, interlamellar and interstack voids using the notation in Neretnieks et al. (2009). However, as with the formulations derived by Gens and Alonso (1992), the approach taken in this thesis does not characterise that topology. Only one macroscopic variable, the microstructural void ratio $e_{\mathrm{m}}$ ( $e_{\mathrm{m}}=$ volume of voids in the microstructure per volume of clay mineral), is used in this study to describe the intra-aggregate porosity (microporosity). The aggregate is treated as a microstructure support scale (in the sense proposed by Pachepsky et al., 2006), thus abstracting its internal complexity.

(a)

Small distance, attraction dominates
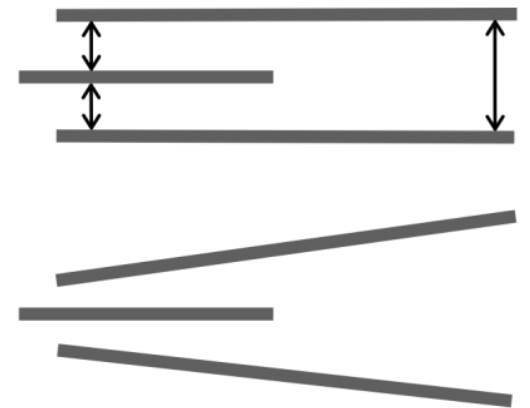

Large distance, repulsion dominates

Sheets separate where repulsion dominates and contract where attraction dominates (b)

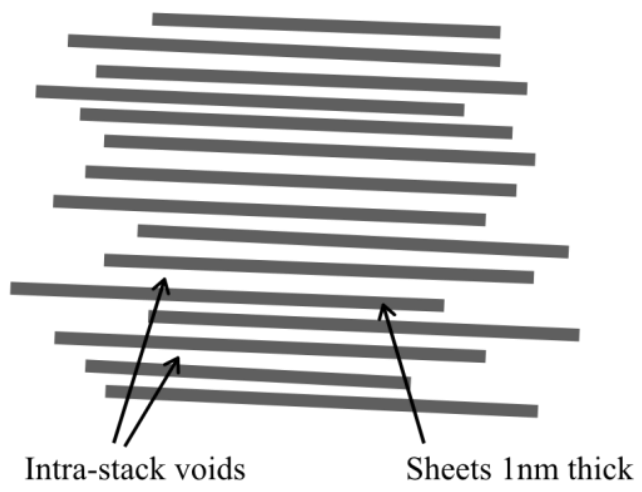

See heterogeneity in distance (c)

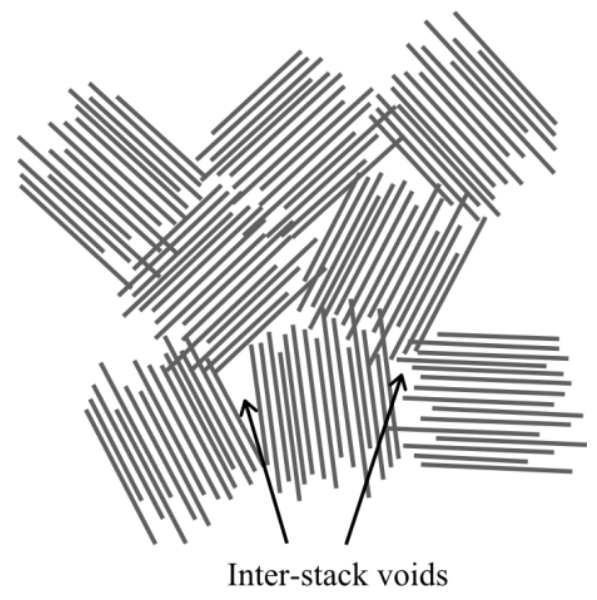

Figure 2. (a) Sheets defining heterogeneity in the interior of a stack. (b) Arrangement of sheets forming a stack. (c) Arrangement of stacks in a compacted bentonite. Adapted from Neretnieks et al. (2009). 
This abstraction approach is not new because it is already implicit in the concept of the 'average separation' or 'mean distance' between sheets, $\lambda^{*}$ (see, for example, Bourg et al., 2006; Karnland et al., 2005; Zhang et al., 1995), which is related to $e_{\mathrm{m}}$ according to the following equation:

$$
e_{\mathrm{m}}=\lambda^{*} / \delta_{S}
$$

where $\delta_{\mathrm{S}}$ is the sheet thickness, which is approximately $1 \mathrm{~nm}$. In Equation $1, \lambda^{*}$ corresponds to a real physical magnitude (the 'true' distance between sheets) only if the aggregates are formed by parallel stacks with only one sheet per stack. This can be assumed to be true of $\mathrm{Na}$ bentonite when the aggregate has a very open structure and both $\lambda^{*}$ and $e_{\mathrm{m}}$ have large values. However, for 'dry' clays, where $\lambda^{*}$ can be as small as 0.3-0.5 nm (Pusch and Yong, 2006), $\lambda^{*}$ must be considered an estimate of the average distance between sheets.

In the past, several equations have been proposed for estimating the value of $\lambda^{*}$. In this thesis, the equation proposed by Low and co-workers (see Low, 1979, 1980, 1987; Low and Margheim, 1979) has been adopted. According to Zhang et al. (1995), the equation can be formulated as follows:

$$
\pi / P_{\text {АTM }}+1=b \cdot \exp \left(k / \lambda^{*}\right)
$$

where $\pi$ is the swelling pressure, $P_{\text {ATM }}$ is the reference atmospheric pressure, and $b$ and $k$ are model parameters. Using Equation 1, Equation 2 can be rewritten as a function of $e_{\mathrm{m}}$ as follows:

$$
\frac{1}{e_{\mathrm{m}}}=\frac{1}{e_{\mathrm{mO}}}+\frac{1}{k} \cdot \operatorname{Ln}\left(\pi / P_{\mathrm{ATM}}+1\right)
$$

where the microstructural deformability parameter $k$ introduced in Equation 2 is maintained but the $b$ parameter has been replaced by $e_{\mathrm{mo}}$, which is the microstructural void ratio when $\pi=0$ (that is, when only the atmospheric pressure is applied). 
Equation 2 was proposed for the gels of oriented clay particles (Zhang et al., 1995) in which $\lambda^{*}$ had values larger than $1 \mathrm{~nm}$, that is, microstructural void ratios greater than 1 . Therefore, its validity must be questioned for lower values of $e_{\mathrm{m}}$ when the aggregates maintain a high level of internal structure.

Data obtained by Montes-H et al. (2003b) can be used to examine this issue. In their experiments, the initial water content of the bentonite was $10.8 \%$. Assuming that virtually all of the water was in the micropores, it follows that the initial microstructural void ratio $e_{\mathrm{m} \text {-ini }}$ was equal to 0.29 , which was far below the range of values suggested by Zhang et al. (1995). It is interesting to note that 0.29 is close to the reference intra-aggregate void ratio that was identified by Romero et al. (2011) for several soils. This void ratio is associated with a situation in which the macropores are completely empty even though the micropores remain saturated.

The surface area variations determined by Montes-H et al. (2003b) in individual MX 80 bentonite aggregates were examined using digital analysis of images obtained from ESEM. In the tests, the $R H$ increased from $2.5 \%$ to the values indicated in Table 1. It is interesting to note that after each swelling step, the individual aggregate identified in each test was subjected to a shrinkage process, returning to an $R H$ of $2.5 \%$. A new swelling step was applied afterwards. In all cases, fully reversible behaviour was observed, with the same initial surface area always being recovered at an $R H=2.5 \%$. This result agrees with the proposals of other researchers (see, for example, Gens and Alonso, 1992; Hueckel, 1992; Quirk, 1994), and also supports the validity of expressions such as Equation 3, in which only one-to-one expressions of $e_{\mathrm{m}}$ are considered.

\begin{tabular}{ccccc}
\hline $\boldsymbol{R} \boldsymbol{H}_{\text {ini }}(\mathbf{\% )}$ & $\boldsymbol{R} \boldsymbol{H}_{\text {end }}(\mathbf{\% )}$ & $\boldsymbol{\pi}_{\text {end }}(\mathbf{M P a})$ & $\boldsymbol{S}_{\text {end }}(\mathbf{\%})$ & $\boldsymbol{e}_{\text {m-end }}$ \\
\hline 2.5 & 55 & 78 & 6.79 & 0.310 \\
2.5 & 60 & 67 & 9.01 & 0.316 \\
2.5 & 65 & 56 & 9.91 & 0.319 \\
2.5 & 70 & 46 & 11.51 & 0.324 \\
2.5 & 75 & 37 & 12.32 & 0.326 \\
2.5 & 80 & 29 & 13.43 & 0.329 \\
2.5 & 85 & 21 & 15.21 & 0.334 \\
2.5 & 90 & 14 & 20.99 & 0.351 \\
\hline
\end{tabular}

Table 1. Relative Humidity $R H$, swelling pressure $\pi_{\text {end }}$, swelling strain $S_{\text {end }}$ and microstructural void ratio $e_{\mathrm{m} \text {-end }}$ at the end of each of the swelling steps in the test conducted by Montes-H et al. (2003b). 
To correlate $R H$ to $\pi$, and thus to be able to use Equation 3, the chemical potential of the (microstructural) water inside the aggregate $\mu_{\mathrm{m}}$ can be calculated in the following manner, according to Edlefsen and Anderson (1943):

$$
\mu_{\mathrm{m}}-\mu_{\mathrm{vO}}(T)=R T \operatorname{Ln}(R H)
$$

where $\mu_{\mathrm{vo}}(T)$ is the chemical potential of water vapour over a flat surface of pure water at an absolute temperature $T$, and $R$ is the universal gas constant. However, according to Karnland et al. (2005), $\mu_{\mathrm{m}}$ can also be defined as follows:

$$
\mu_{\mathrm{m}}=\mu_{\mathrm{vO}}(T)+R T \operatorname{Ln}\left(p_{\mathrm{C}} / p_{\mathrm{O}}\right)+R T \operatorname{Ln}\left(p_{\mathrm{IE}} / p_{\mathrm{O}}\right)+\frac{W M M}{\rho_{\mathrm{W}}} \sigma
$$

where the reference pressure $p_{0}$ is the vapour pressure set by pure water (that is, the pressure of water vapour in equilibrium with free pure water), $p_{\mathrm{C}}$ is the vapour pressure set by the clay (that is, the change from $p_{0}$ induced by clay particles), $p_{\mathrm{IE}}$ is the vapour pressure set by the ions (the change from $p_{0}$ caused by the presence of ions), WMM is the water molecular mass, $\sigma$ is the mean net stress applied to the soil, and $\rho_{\mathrm{W}}$ is the water density. Several authors have shown that the density of interlayer water on clay sheets may be higher than that of free water. However, in this thesis, as suggested by Tournassat and Appelo (2011), both densities are assumed to be equal for modelling purposes.

In the ESEM chamber, $\sigma$ was zero. Based on the water activity values given by Montes-H et al. (2003b), it can be assumed that $p_{\mathrm{IE}} \approx p_{0}$ in the tests. Keeping these simplifications in mind, as well as the fact that under low salinity conditions it is common to define the swelling pressure $\pi$ as follows:

$$
R T \operatorname{Ln}\left(p_{\mathrm{C}} / p_{\mathrm{O}}\right)=-\frac{W M M}{\rho_{\mathrm{W}}} \pi
$$

and therefore:

$$
\mu_{\mathrm{m}}-\mu_{\mathrm{vO}}(T)=-\frac{W M M}{\rho_{\mathrm{W}}} \pi
$$

which yields the following equation: 


$$
\pi=-\frac{R T}{W M M} \rho_{\mathrm{W}} \operatorname{Ln}(R H)
$$

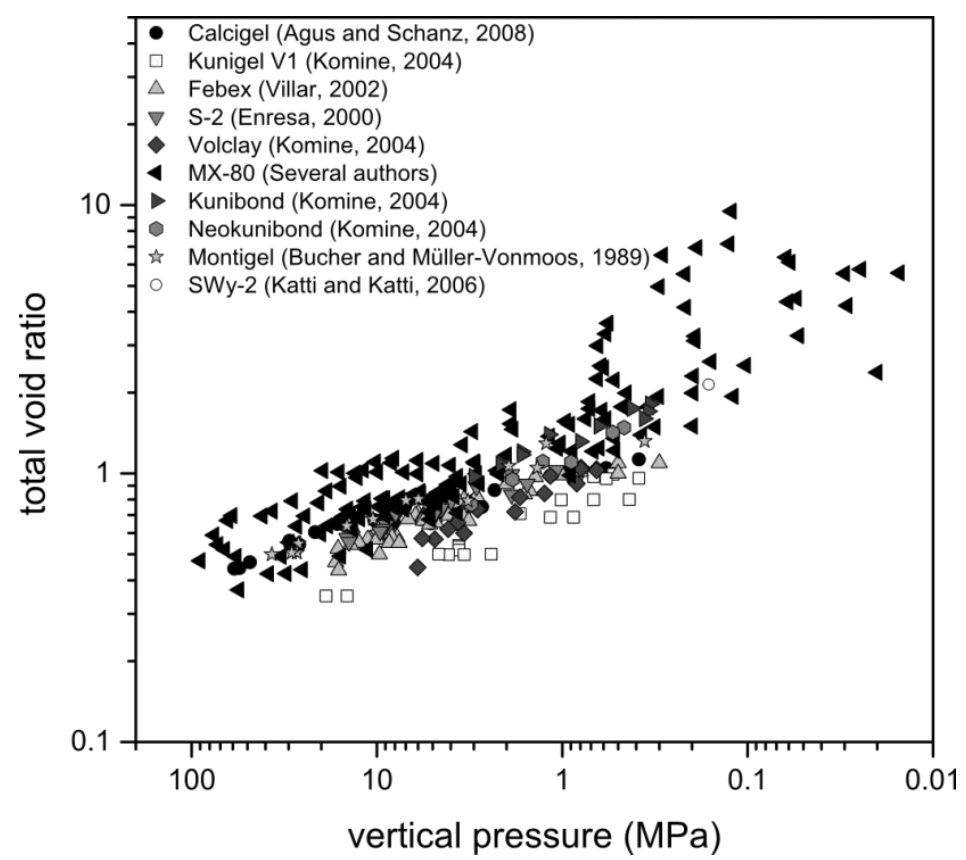

Figure 3. Compilation of void ratios associated with swelling pressure tests carried out for several bentonite samples. Data for MX-80 from Borgesson et al. (1996), Dueck et al. (2010), Karnland et al. (2005, 2006, 2011), Man and Martino (2009), Rautioaho and Korkiala-Tanttu (2009) and Swedish Nuclear Power Inspectorate (2005).

Therefore, for an $R H$ of $2.5 \%$ and an initial temperature of $50^{\circ} \mathrm{C}, \pi$ was approximately $551 \mathrm{MPa}$. This is a very high value, as can be observed in Fig. 3, which shows the results from many 'conventional' swelling pressure tests (isochoric tests usually carried out in adapted oedometers). From the dry density and mean distance between sheets data provided by these tests, it was not possible to differentiate between macro and micro void ratio values. However, the total void ratio values obtained indicate that for swelling pressure values as high as 551 MPa (much higher than the experimental values shown in Fig. 3), it seems reasonable to assume void ratio values as low as 0.29 (lower than the majority of the data in the figure). The consistency of this microstructural void ratio value is even more evident if the validity of the basic hypothesis used to derive it is considered, i.e., that practically all of the existing water in the soil at the beginning of the test was contained inside the aggregates. For this purpose, it is useful to express the relative humidity in terms of an 'equivalent environmental suction' $S_{\text {ENV }}$. This yields an equation similar to Equation 8, with $s_{\text {ENV }}$ instead of $\pi$ (see 
Romero, 1999, for example). According to the model for the suction-water content relationship proposed by Romero (1999), when this suction is larger than $2 \mathrm{MPa}$, a large proportion of the water is in intra-aggregate pores, and becomes fundamentally intrastack water (as illustrated in Fig. 2) when suction is larger than $160 \mathrm{MPa}$. Therefore, it is reasonable to assume that at $551 \mathrm{MPa}$, the water is microstructural water.

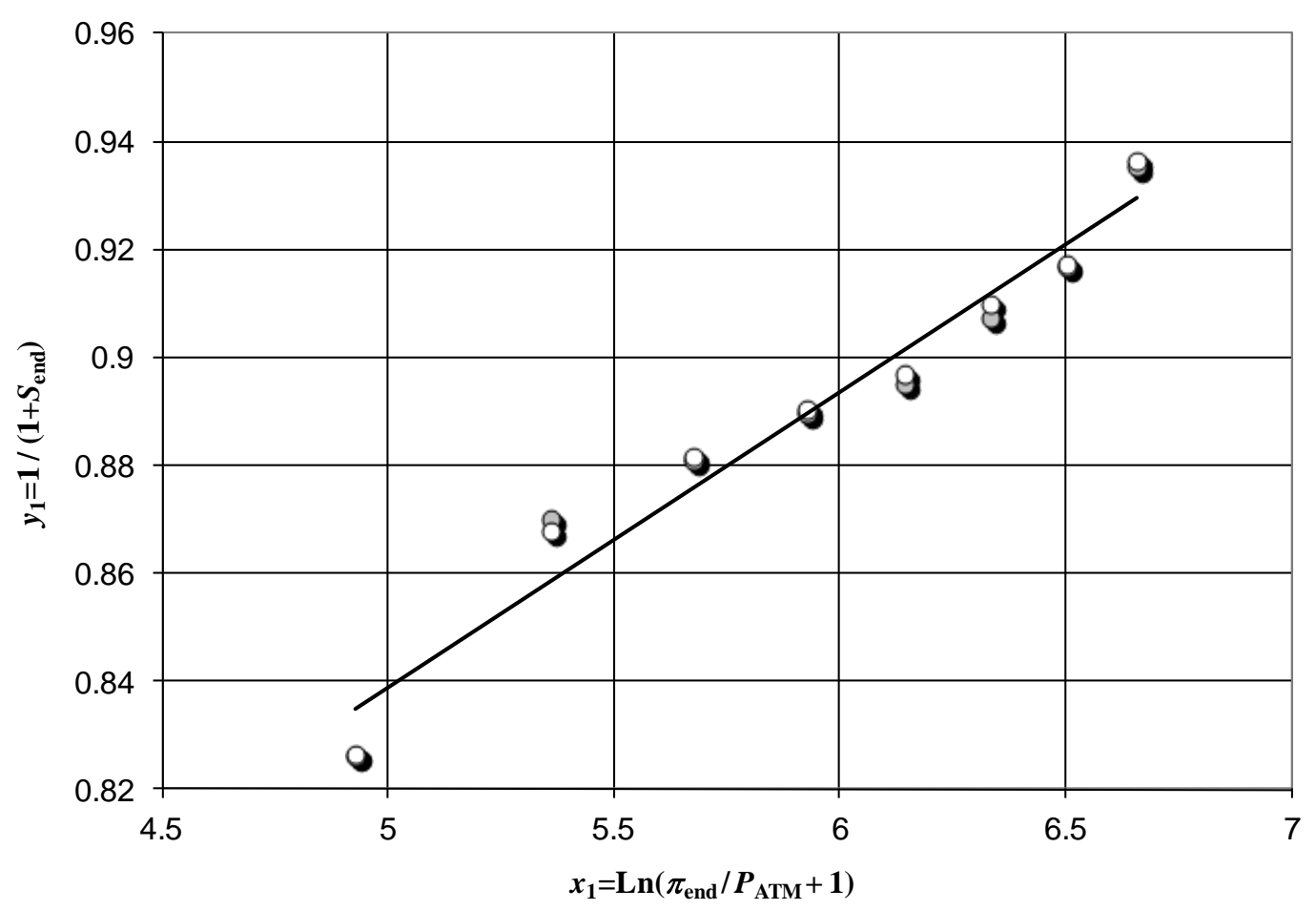

Figure 4. Data points $\left(x_{1}, y_{1}\right)$ (see Equation 11) obtained from the tests conducted by Montes- $\mathrm{H}$ et al. (2003b).

It should be indicated that the concept of 'swelling pressure' is often used to refer to different processes. When this term refers to the results of swelling pressure tests (for example, the standard ASTM D4546-08 (ASTM, 2008)), it has a mechanistic meaning, depending on the test conditions. The swelling pressure is the response to a boundary condition, and depends also on the initial conditions of the bentonite, and on the deformability of its macrostructure. However, when authors such as Low and co-workers (see, for example, Zhang et al., 1995, and references therein) use this concept, it has a thermodynamic meaning that is directly related to the chemical potential of microstructural water. It is also the case of this chapter. Moreover, it is worth to stress that, in accordance with 
Equations 5 and 6, the swelling pressure was not interpreted as the pressure exerted by the aggregates when swelling occurs in any kind of condition. Rather, it was interpreted as the pressure exerted when the aggregates swell in pure water, that is, when all the vapour pressure is set by the clay skeleton.

In Table 1, Equation 8 was used to define the final value of the swelling pressure of the aggregates $\pi_{\text {end }}$ in the tests carried out by Montes- $\mathrm{H}$ et al. (2003b). Moreover, Table 1 also includes the microstructural void ratio values at the end of each of the swelling steps, $e_{\mathrm{m}-\mathrm{end}}$. These values were derived from the swelling strain $S_{\text {end, }}$ defined as the relative difference ratio between the aggregate surface area $A$ at the start, $A_{\mathrm{ini}}$, and at the end, $A_{\mathrm{end}}$ of the tests:

$$
S_{\text {end }}=\frac{A_{\text {end }}-A_{\text {ini }}}{A_{\text {ini }}} \approx \frac{e_{\mathrm{m} \text {-end }}-e_{\text {m-ini }}}{e_{\text {m-ini }}}=\frac{e_{\mathrm{m} \text {-end }}}{e_{\text {m-ini }}}-1
$$

To obtain the values of $e_{\mathrm{m} \text {-end }}$ included in Table 1 , it was assumed that $e_{\mathrm{m} \text {-ini }}=0.29$. Consequently, if Equation 3 is valid, the following linear relationship must be satisfied:

$$
y_{1}=\frac{e_{\mathrm{m}-\mathrm{ini}}}{e_{\mathrm{m}-\mathrm{end}}}=\frac{e_{\mathrm{m}-\mathrm{ini}}}{e_{\mathrm{mO}}}+\frac{e_{\mathrm{m}-\mathrm{ini}}}{k} \cdot \operatorname{Ln}\left(\pi_{\mathrm{end}} / P_{\mathrm{ATM}}+1\right)=A+B x_{1}
$$

where, for convenience, the ratio $e_{\mathrm{m} \text {-ini }} / e_{\mathrm{m} \text {-end }}$ is denoted as $y_{1}$, the expression $\operatorname{Ln}\left(\pi_{\mathrm{end}} / P_{\mathrm{ATM}}+1\right)$ is identified as $x_{1}$, and the parameters $e_{\mathrm{m} \text {-ini }} / e_{\mathrm{mo}}$ and $e_{\mathrm{m} \text {-ini }} / k$, obtained respectively from $e_{\mathrm{mo}}$ and $k$ (model parameters defined after Equation 3), are designed by the constants $A$ and $B$. In accordance with this notation, the points $\left(x_{1}, y_{1}\right)$ derived from Table 1 have been plotted in Fig. 4. The linear fit is very satisfactory, with a squared Pearson coefficient value of 0.96 . Therefore, it is reasonable to accept Equation 3 as a valid constitutive equation for approximating the volumetric deformability of aggregates, even for very low values of microstructural porosity. 


\section{Mass exchange between macropores and aggregates}

The previous section analyses how the microstructural void ratio varies when, after the $R H$ was increased, the aggregate reached equilibrium and its surface area remains constant. However, when the $R H$ in the ESEM chamber increases, a transient process occurs before reaching equilibrium, as observed in Figs. 5a and b. As the $R H$ increases, the chemical potential of the aggregate boundary becomes larger (Equation 4), while the chemical potential in the interior of the aggregate remains unchanged. This produces an imbalance that leads to a transient process in which a water mass exchange, $c_{\mathrm{m}}$, from the aggregate boundary to the intraaggregate porosity (from the macropores to the micropores) is registered. This causes $e_{\mathrm{m}}$ to increase (i.e., swelling occurs) until the chemical potential of the aggregate equals that of the chamber. If a classical linear approach is used (de Groot and Mazur, 1984), the water mass exchange of water may be determined from the following equation:

$$
c_{\mathrm{m}}=\alpha \cdot\left(\mu_{\mathrm{M}}-\mu_{\mathrm{m}}\right)
$$

where $\alpha$ is a phenomenological transfer coefficient and $\mu_{\mathrm{M}}$ is the chemical potential of the water in the aggregate boundary, that is, in the macrostructural voids.

According to Edlefsen and Anderson (1943), it may be computed as:

$$
\mu_{\mathrm{M}}=\mu_{\mathrm{vO}}(T)-\frac{W M M}{\rho_{\mathrm{W}}} \cdot s+R \cdot T \cdot \operatorname{Ln} x_{\mathrm{M}}
$$

where $s$ is the macrostructural water matric suction, and, assuming a dilute solution, $x_{\mathrm{M}}$ is the mole fraction of the macropore water $\left(x_{\mathrm{M}}=n_{\mathrm{M}} / n_{\mathrm{L}}\right.$, where $n_{\mathrm{M}}$ is the number of moles of macrostructural water, and $n_{\mathrm{L}}$ is the total number of moles of macrostructural liquid: water plus dissolved salts). 
a)

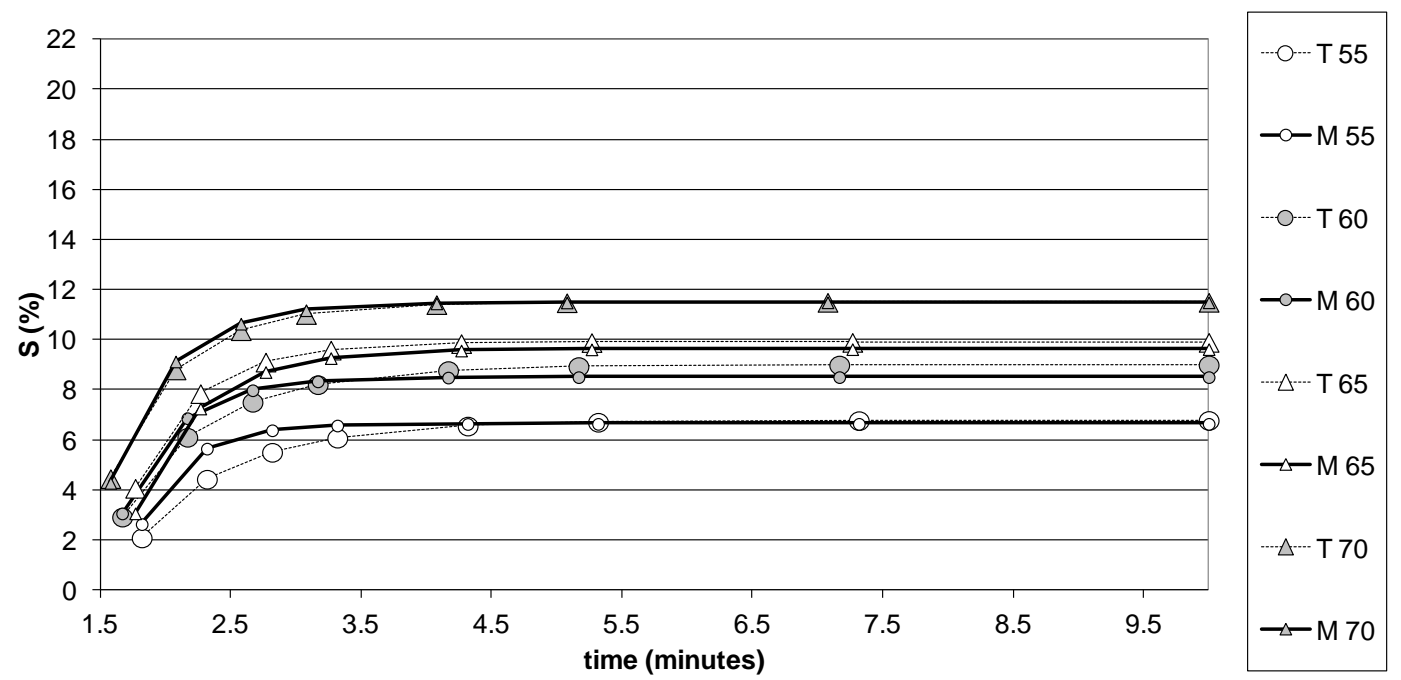

b)

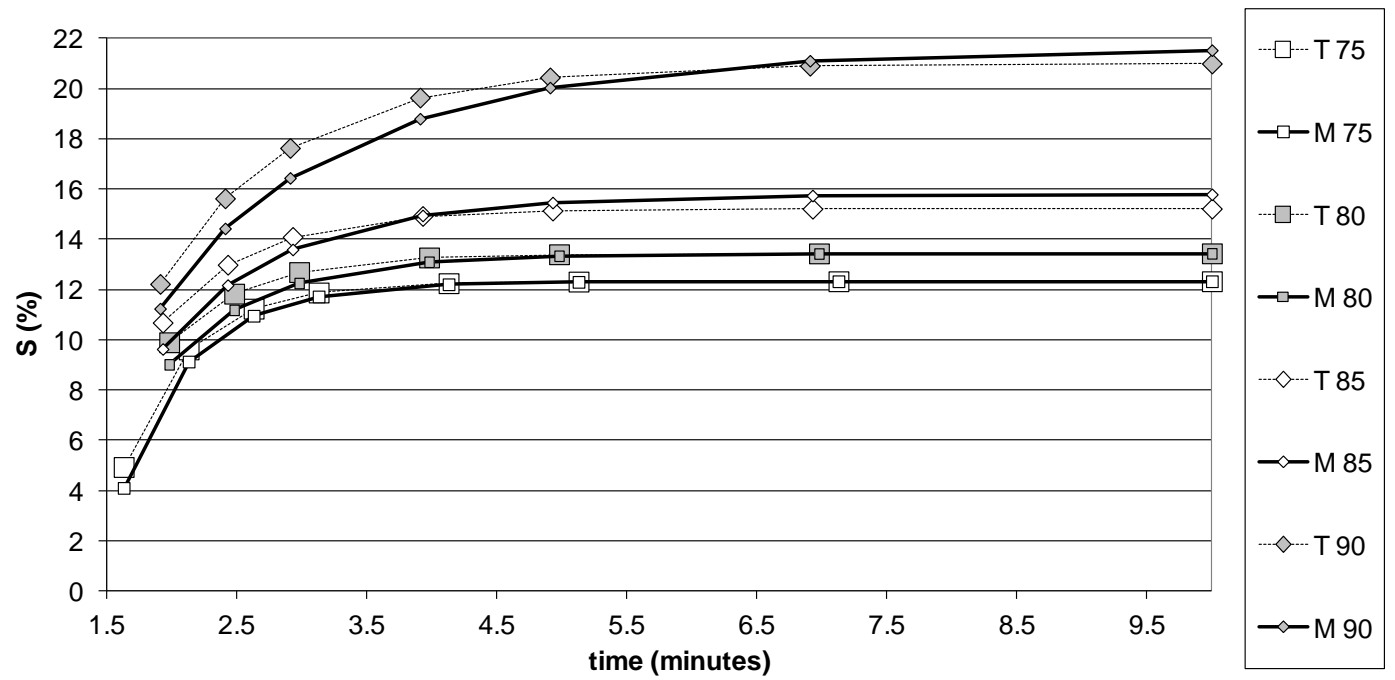

Figure 5. Test data (T) and model values (M) from swelling tests conducted by Montes-H (2003b), varying the $\mathrm{RH}$ from $2.5 \%$ to the values indicated in the figure legends (a) $55 \%, 60 \%, 65 \%$ and 70\%; (b) 75\%, 80\%, 85\% and 90\%.

The formulation in Equation 11 is similar to the linear relationship used by Gens et al. (2011), which is written in terms of the total water potential. Navarro and Alonso (2001) and Alonso and Navarro (2005) adopted a non-linear formulation, treating chemical potentials as thermodynamic forces, in analysing the secondary compression of a number of clays. The value of $\alpha$ was not taken as constant but rather assumed to increase as the ratio $\mu_{\mathrm{M}} / \mu_{\mathrm{m}}$ increased. On a completely different scale, Ferrage et al. (2007) also identified transient water mass exchange processes in which the kinetics depended on the imbalance. These researchers analysed the dehydration occurring at the crystal scale for water located 
exclusively in the interlayer of a Ca montmorillonite. Their data are plotted in Fig. 6 , where the time required to reach $90 \%$ of the equilibrium value $t_{90}$ is shown for the relative abundance of bihydrated $(\% 2 \mathrm{~W})$ and dehydrated layers $(\% 0 \mathrm{~W})$, as well as for the layer thickness of monohydrated (LT1W) and bihydrated (LT2W) layers. In all cases, at the initial equilibrium conditions the temperature was $25^{\circ} \mathrm{C}$ and the relative humidity was $60-65 \%$. The temperatures identified as 'boundary temperatures' in Fig 6 were imposed until a new equilibrium was reached. The amount of water absorbed in the smectite interlayer was determined using X-ray diffraction profile modelling. The reference value defined by the saturation pressure of water vapour over a flat surface of pure water increased with increasing temperature. Consequently, the relative humidity decreased, and $\mu_{\mathrm{M}}$ became smaller than $\mu_{\mathrm{m}}$, giving rise to a flow towards the macrostructure and to dehydration of the microstructure. For larger temperature differences, the ratio $\mu_{\mathrm{m}} / \mu_{\mathrm{M}}$ was larger, and the flow was faster (lower $t_{90}$ ), as shown in Fig 6. Although the scale of the interlamellar water phenomenon makes it difficult to identify patterns that characterise processes at the aggregate level, it raised the consideration of using the formulation proposed by Alonso and Navarro (2005). However, those authors proposed the formulation to model secondary compression processes, in which the differences between $\mu_{\mathrm{M}}$ and $\mu_{\mathrm{m}}$ are far inferior to the ones produced in the swelling processes considered here. Therefore, the validity of the formulation was assessed by analysing the transient processes shown in Figs. 5a and b.

The variation of $\pi$ was determined using Equation 8, the evolution of $e_{\mathrm{m}} / e_{\operatorname{mini}}$ was calculated using Equation 9 taking the current aggregate surface area $A$ instead of its final value $A_{\text {end. }}$ The evolution of $A$ was experimentally determined by Montes- $\mathrm{H}$ et al. (2003b).

Since the variations in $e_{\mathrm{m}}$ are a consequence of the hydration process, when applying the mass-balance equation proposed by Navarro and Alonso (2001) to an individual aggregate, the time derivative of the microstructural void ratio is given by the following equation: 


$$
\frac{d e_{\mathrm{m}}}{d t}=\left(1+e_{\mathrm{m}}\right) \frac{c_{\mathrm{m}}}{\rho_{\mathrm{W}}}
$$

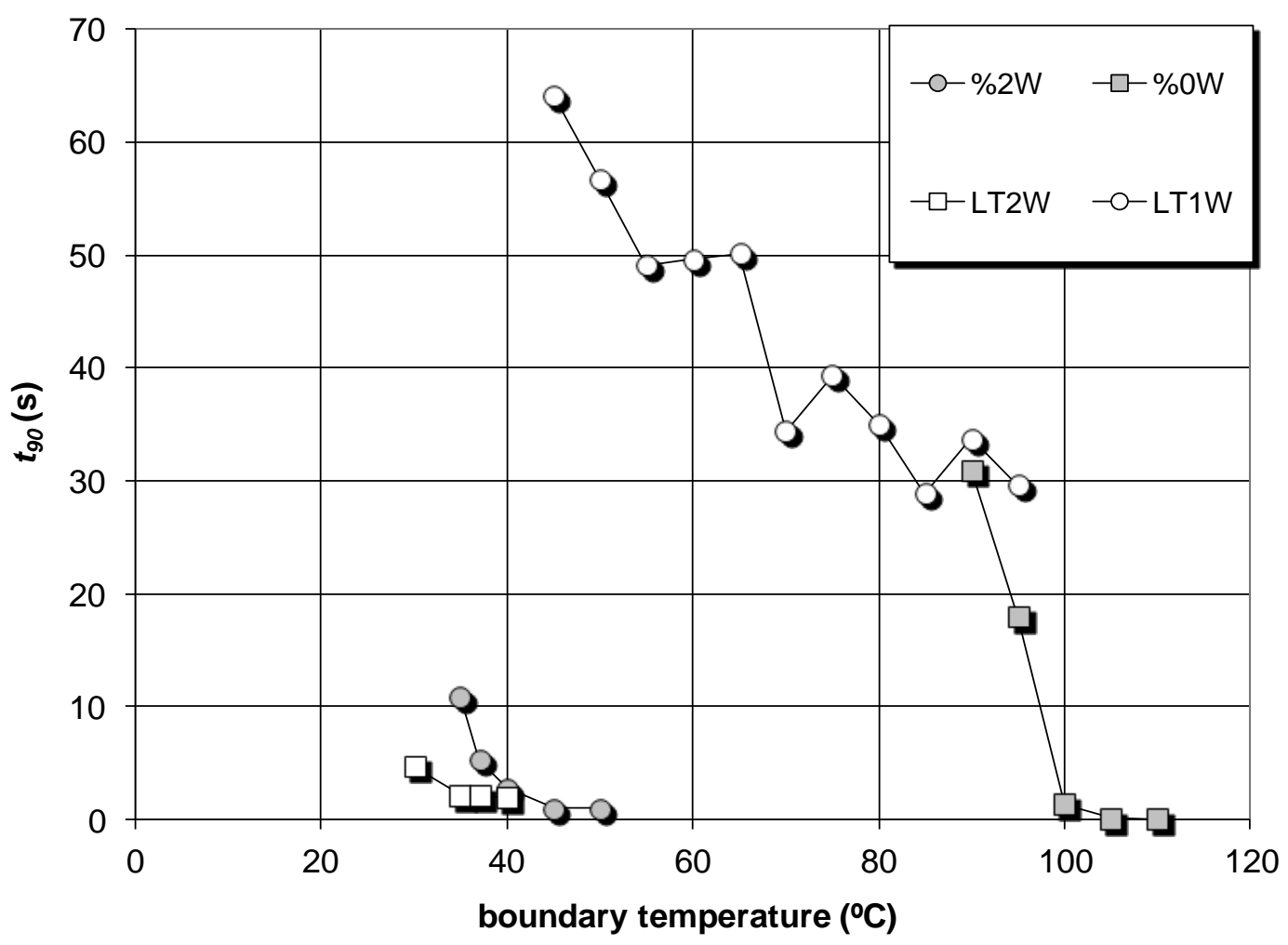

Figure 6. Time $t_{90}$ required to reach $90 \%$ of the equilibrium value for the relative abundance of bihydrated $(\% 2 \mathrm{~W})$ and dehydrated layers $(\% 0 \mathrm{~W})$, as well as for the layer thickness of monohydrated (LT1W) and bihydrated layers (LT2W).

Thus, applying Equation 9 not only to $S_{\text {end }}$ but also for any value $S\left(\equiv\left[A-A_{\text {ini }}\right] / A_{\text {ini }}\right)$ it is obtained:

$$
\frac{c_{\mathrm{m}}}{\rho_{\mathrm{W}}}=\frac{e_{\mathrm{m}-\mathrm{ini}}}{1+e_{\mathrm{m}-\mathrm{ini}}(1+S)} \frac{d S}{d t}
$$




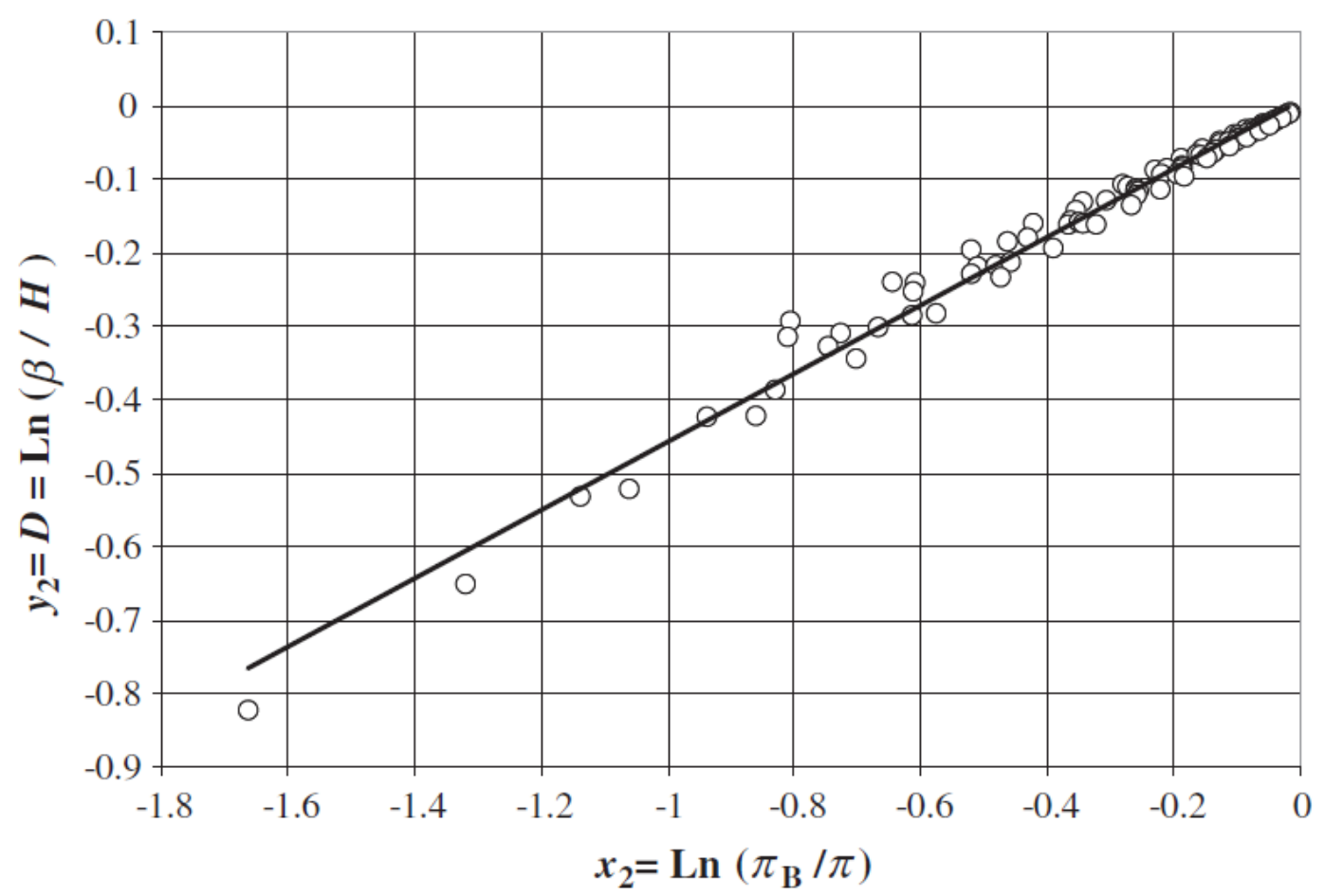

Figure 7. Data points $\left(x_{2}, y_{2}\right)$ (see Equation 16) obtained from the data published by Montes-H et al. (2003b).

In the non-linear formulation for $\alpha$ proposed by Alonso and Navarro (2005), $c_{\mathrm{m}}$ can be calculated as follows:

$$
\frac{c_{\mathrm{m}}}{\rho_{\mathrm{W}}}=\beta \cdot\left(\pi-\pi_{\mathrm{B}}\right)=H\left(\frac{\pi_{\mathrm{B}}}{\pi}\right)^{C}\left(\pi-\pi_{\mathrm{B}}\right)
$$

where the constant $\beta$ is equal to $\alpha \cdot W M M \cdot\left(\rho_{\mathrm{w}}\right)^{-1}$, and Equation 7 has been used to transform $\mu_{\mathrm{m}}$ into $\pi$. The value of $\pi_{\mathrm{B}}$ can be determined from $\mu_{\mathrm{M}}$ and may be interpreted as the water pressure potential that the boundary imposes on the aggregate. $H$ and $C$ are constitutive parameters. $H$ defines the water mass transfer at the end of the process $\left(\pi=\pi_{\mathrm{B}}\right)$, and $C$ defines the way in which the mass transfer term changes as $\pi$ approaches $\pi_{\mathrm{B}}$.

Therefore, if Alonso and Navarro's (2005) model can be applied to aggregates, it is obtained, by introducing Equation 14 in Equation 15, that the following linear relationship will be satisfied:

$$
y_{2}=\operatorname{Ln} \beta=\operatorname{Ln}\left(\frac{e_{\mathrm{m}-\text { ini }}}{1+e_{\mathrm{m} \text {-ini }}(1+S)} \frac{d S}{d t}\right)-\operatorname{Ln}\left(\pi-\pi_{\mathrm{B}}\right)=\operatorname{Ln} H+C \operatorname{Ln} \frac{\pi_{\mathrm{B}}}{\pi}=D+C x_{2}
$$


For notational convenience, as done with $x_{1}$ and $y_{1}$ in Equation 10, the variables $x_{2}$ and $y_{2}$ have been defined in Equation 16, as well as the parameter $D$ (note that the true model parameters are $H$ and $C)$. The pairs $\left(x_{2}, y_{2}\right)$ obtained from the experimental data of Montes-H et al. (2003b) are shown in Fig 7. The linear correlation is very good (squared Pearson coefficient of 0.98). The values of $C$ and $D$ are shown in Table 2 . These values are consistent with those identified for other clays by Navarro and Alonso (2001) and by Alonso and Navarro (2005). Hence, the results support the validity of the formulation defined by Equation 15.

For the values of $C$ and $D$ in Table 2, the agreement between the numerical simulation results (i.e., the numerical time integration of $S$, from Equations 14 and 15, using the explicit Euler method) and the test values shown in Figs. 5a and b is satisfactory. It must be emphasised that the formulation proposed in Equation 3 was used to obtain the value of $\pi$ that was used in the calculation of the $\left(x_{2}, y_{2}\right)$ points in Fig. 7 and in the time integration of $S$. Consequently, the fits shown in Figs. $5 \mathrm{a}$ and $\mathrm{b}$ encourage confidence not only in the water mass exchange term proposed in Equation 15, but also in the state function defined by Equation 3.

\begin{tabular}{ccc}
\hline $\boldsymbol{R} \boldsymbol{H}_{\text {end }}(\mathbf{\% )}$ & $\mathbf{C}$ & $\mathrm{D}$ \\
\hline 55 & 0.367 & -20.04 \\
60 & 0.389 & -19.58 \\
65 & 0.410 & -18.98 \\
70 & 0.423 & -18.81 \\
75 & 0.435 & -18.55 \\
80 & 0.448 & -18.45 \\
85 & 0.464 & -18.22 \\
90 & 0.491 & -17.96 \\
\hline
\end{tabular}

Table 2. Parameters $C$ and $D$ in Equation 16 identified from the test conducted by Montes-H et al. (2003b).

When implementing the model defined by Equations 3 and 15 in a general bentonite constitutive model such as BExM, it will be considered that there may not be chemical equilibrium between macro and microstructural water. This way, the mass exchange will be modelled through Equation 15, and Equation 3 will be used to compute $\pi$ from $e_{\mathrm{m}}$. As a result, a new state variable, $e_{\mathrm{m}}$, is introduced in the analysis, and a new mass balance equation should be considered. That is, microstructural and macrostructural water mass balance equations should be set 
apart since equilibrium is not assumed between both types of water. Several authors have introduced approaches of such kind (see Alonso et al., 2011, and Gens et al., 2011), although they have implemented formulations different from that stated in Equations 3 and 15. The FEM numerical model which incorporates, together with the BExM, Equations 3 and 15 in a multiphysics environment, will be described in the next chapter.

\section{Conclusions}

A model for double porosity in bentonite has been developed using an approximation in which aggregates are treated as support scale, avoiding the characterisation of their complex internal topology. The level of structuring in aggregates as a whole is characterised by the microstructural void ratio $e_{\mathrm{m}}$. Equation 3, a one-to-one model based on the formulation by Zhang et al. (1995), is proposed for use in defining this macroscopic variable. Although this formulation was originally proposed for gels of oriented clay particles in which the void ratios were considerably larger than those usually found in compacted bentonite aggregates, the analysis of the data obtained from Montes- $\mathrm{H}$ et al. (2003b) for individual bentonite aggregates has shown the formulation to be valid even for very small microstructural porosity values. Experimental results obtained by Montes-H et al. (2003b) have also been used to assess the validity of using Equation 15 (Alonso and Navarro, 2005) to determine the rate of water mass exchange produced between macropores and inter-aggregate pores when there is no chemical potential equilibrium between macro- and microstructural water. A satisfactory fit to the transient processes analysed has been obtained. Again data from Montes-H et al. (2003b), directly associated with aggregates (i.e., not segregated from macrostructural information according to some hypothesis concerning macrostructural behaviour), was used in this analysis. The results obtained encourage confidence in the use of Equations 3 and 15 as a constitutive framework for defining the volumetric deformability and mass exchange of soil microstructures.

However, without underestimating the importance of the results obtained, caution is advised concerning the range of applicability of this constitutive framework. It 
would be useful to improve the range of its validity by analysing a larger number of experimental results. Unfortunately, the data needed for this type of analysis are currently very scarce, which is why more tests such as those conducted by MontesH (2005) and Montes-H et al. (2003a; 2003b; 2005a; 2005b) are needed. This is particularly true if tomographic techniques are used to obtain $3 \mathrm{D}$ data of the volumetric behaviour of bentonite aggregates.

\section{Acknowledgements}

This research was financed in part by B+TECH Oy (Finland) under a POSIVA Oy project and by the FPU Grant AP2009-2134 from the Spanish Ministry of Education awarded to Ms. Asensio.

\section{References}

Alonso, E.E., Gens, A., Hight, D.W., 1987. Special problem soils: general report. Proceedings of the 9th Conference on Soil Mechanics and Foundation Engineering 3, pp. 1087-1146.

Alonso, E.E., Gens, A., Josa, A., 1990. A constitutive model for partially saturated soils. Geotechnique 40 (3), 405-430.

Alonso, E.E., Navarro, V., 2005. Microstructural model for delayed deformation of clay: loading history effects. Can. Geotech. J. 42 (2), 381-392.

Alonso, E.E., Romero, E., Hoffmann, C., 2011. Hydromechanical behaviour of compacted granular expansive mixtures: experimental and constitutive study. Geotechnique 61 (4), 329-344.

Alonso, E.E., Vaunat, J., Gens, A., 1999. Modelling the mechanical behaviour of expansive clays. Eng. Geol. 54 (1-2), 173-183.

ASTM Standard D4546-08, 2008. Standard Test Methods for One-Dimensional Swell or Collapse of Cohesive Soils. ASTM International, West Conshohocken, PA. http://dx.doi.org/10.1520/D4546-08.

Borgesson, L., Karnland, O., Johannesson, L.E., 1996. Modelling of the physical behaviour of clay barriers close to water saturation. Eng. Geol. 41, 127-144.

Bourg, I.C., Sposito, G., Bourg, A.C.M., 2006. Tracer diffusion in compacted,water-saturated bentonite. Clays Clay Miner. 54 (3), 363-374.

Cadene, A., Durand-Vidal, S., Turq, P., Brendle, J., 2005. Study of individual Namontmorillonite particles size, morphology, and apparent charge. J. Colloid Interface Sci. 285(2), 719-730. 
Chegbeleh, L.P., Nishigaki,M., Akudago, J.A., Alim, M.A., Komatsu,M., 2008. Concepts of repository and the functions of bentonite in repository environments: a state of the art review. J. Fac. Environ. Sci. Technol. Okayama Univ. 13 (1), 1-5.

Collins, K., 1984. Characterization of expansive soil microfabric. Proceedings of the 5th International Conference on Expansive Soils, Adelaide, pp. 37-43.

Collins, K.,McGown, A., 1974. The formand function of microfabric features in a variety of natural soils. Geotechnique 24 (2), 223-254.

Cui, Y.J., Yahia-Aissa, M., Delage, P., 2002. A model for the volume change behavior of heavily compacted swelling clays. Eng. Geol. 64 (2-3), 233-250.

de Groot, S.R., Mazur, P., 1984. Non-Equilibrium Thermodynamics. Dover Publications.

Dueck, A., Börgesson, L., Johannesson, L.E., 2010. Stress-strain relation of bentonite at undrained shear. Laboratory tests to investigate the influence of material composition and test technique. Technical Report TR-10-32. Svensk Kärnbränslehantering AB, Swedish Nuclear Fuel and Waste Management Co. (Available at http://www.skb.se/upload/publications/pdf/TR-10-32.pdf, last accessed September 2013).

Edlefsen, N.E., Anderson, A.B.C., 1943. Thermodynamics of soil moisture. Hilgardia 15 (2),31-298.

Farulla, C.A., Ferrari, A., Romero, E., 2010. Volume change behaviour of a compacted scaly clay during cyclic suction changes. Can. Geotech. J. 47 (6), 688-703.

Ferrage, E., Kirk, C.A., Cressey, G., Cuadros, J., 2007. Dehydration of Ca-montmorillonite at the crystal scale. Part 2. Mechanisms and kinetics. Am. Mineral. 92 (7),1007-1017.

Gens, A., Alonso, E.E., 1992. A framework for the behaviour of unsaturated expansive clays. Can. Geotech. J. 29 (6), 1013-1032.

Gens, A., Garcia-Molina, A.J., Olivella, S., Alonso, E.E., Huertas, F., 1998. Analysis of a full scale in situ test simulating repository conditions. Int. J. Numer. Anal. Methods Geomech. 22 (7), 515-548.

Gens, A., Vallejan, B., Sanchez, M., Imbert, C., Villar, M.V., Van Geet, M., 2011. Hydromechanical behaviour of a heterogeneous compacted soil: experimental observations and modelling. Geotechnique 61 (5), 367-386.

Hueckel, T.A., 1992. Water-mineral interaction in hygromechanics of clays exposed to environmental loads: a mixture-theory approach. Can. Geotech. J. 29 (6), 1071-1086.

Karnland, O., Muurinen, A., Karlsson, F., 2005. Bentonite swelling pressure in $\mathrm{NaCl}$ solutions. Experimentally determined data and model calculations. In: Alonso, E.E., Ledesma, A. (Eds.), Advances in Understanding Engineered Clay Barriers: Proceedings of the International Symposium on Large Scale Field Test in Granite, Sitges, Barcelona, 12-14 November 2003. Taylor and Francis Group, London, pp. 241-256.

Karnland, O., Olsson, S., Nilsson, U., 2006. Mineralogy and sealing properties of various bentonites and smectite-rich clay materials. Technical Report TR-06-30. Svensk Kärnbränslehantering AB, Swedish Nuclear Fuel and Waste Management Co. (Available at 
http://www.skb.se/upload/publications/pdf/TR-06-30.pdf, last accessed September 2013).

Karnland, O., Olsson, S., Sandén, T., Fälth, B., Jansson, M., Eriksen, T.E., Svärdström, K., Rosborg, B., Muurinen, A., 2011. Long term test of buffer material at the Äspö HRL, LOT project. Final Report on the A0 Test Parcel. Technical Report TR-09-31. Svensk Kärnbränslehantering AB, Swedish Nuclear Fuel and Waste Management Co. (Available at http://www.skb.se/upload/publications/pdf/TR-09-31.pdf, last accessed September 2013).

Lloret, A., Villar, M.V., Sanchez, M., Gens, A., Pintado, X., Alonso, E.E., 2003. Mechanical behaviour of heavily compacted bentonite under high suction changes. Geotechnique 53 (1), 27-40.

Low, P.F., 1979. Nature and properties of water in montmorillonite-water systems. Soil Sci. Soc. Am. J. 43 (4), 651-658.

Low, P.F., 1980. The swelling of clay: II. Montmorillonites. Soil Sci. Soc. Am. J. 44 (4), 667676.

Low, P.F., 1987. Structural component of the swelling pressure of clays. Langmuir 3 (1), $18-25$.

Low, P.F., Margheim, J.F., 1979. The swelling of clay: I. Basic concepts and empirical equations. Soil Sci. Soc. Am. J. 43 (3), 473-481.

Man, A., Martino, J.B., 2009. Thermal, Hydraulic and Mechanical Properties of Sealing Materials. Nuclear Waste Management Organization, Toronto, Canada.

Montes-H, G., 2005. Swelling-shrinkage measurements of bentonite using coupled environmental scanning electron microscopy and digital image analysis. J. Colloid Interface Sci. 284 (1), 271-277.

Montes-H, G., Duplay, J., Martinez, L., Geraud, Y., Rousset-Tournier, B., 2003a. Influence of interlayer cations on the water sorption and swelling-shrinkage of MX80 bentonite. Appl. Clay Sci. 23 (5-6), 309-321.

Montes-H, G., Duplay, J., Martinez, L., Mendoza, C., 2003b. Swelling-shrinkage kinetics of MX80 bentonite. Appl. Clay Sci. 22 (6), 279-293.

Montes-H, G., Fritz, B., Clement, A., Michau, N., 2005a. Modelling of geochemical reactions and experimental cation exchange in MX80 bentonite. J. Environ. Manag. 77 (1), 35-46.

Montes-H, G., Geraud, Y., Duplay, J., Reuschle, T., 2005b. ESEM observations of compacted bentonite submitted to hydration/dehydration conditions. Colloids Surf. A Physicochem. Eng. Asp. 262 (1-3), 14-22.

Montes-Hernandez, G., Duplay, J., Geraud, Y., Martinez, L., 2006. Several textural properties of compacted and cation-exchanged bentonite. J. Phys. Chem. Solids 67 (8),1769-1774.

Navarro, V., Alonso, E.E., 2001. Secondary compression of clays as a local dehydration process. Geotechnique 51 (10), 859-869.

Neretnieks, I., Liu, L., Moreno, L., 2009. Mechanisms and models for bentonite erosion. Technical Report TR-09-35. Svensk Kärnbränslehantering AB, Swedish Nuclear Fuel and 
Waste Management Co. (Available at http://www.skb.se/upload/publications/pdf/TR-0935.pdf, last accessed September 2013).

Pachepsky, Y.A., Guber, A.K., Van Genuchten, M.T., Nicholson, T.J., Cady, R.E., Simunek, J., Schaap, M.G., 2006. Model abstraction techniques for soil-water flow and transport. Division of Fuel, Engineering and Radiological Research. Office of Nuclear Regulatory Research, U.S. Nuclear Regulatory Commission, Washington, D.C., p. 152 (plus 5 appendices).

Pusch, R., 1982. Mineral-water interactions and their influence on the physical behavior of highly compacted Na bentonite. Can. Geotech. J. 19 (3), 381-387.

Pusch, R., 1992. Use of bentonite for isolation of radioactive waste products. Clay Miner. 27 (3), 353-361.

Pusch, R., 1999. Introduction. Session II. Application of microstructural models. Eng. Geol. 54 (1-2), 81-82.

Pusch, R., Moreno, L., 2001. Saturation and permeation of buffer clay. Proceedings of the 6th International Workshop on Key Issues in Waste Isolation Research, Paris, pp. 71-81.

Pusch, R., Weston, R., 2012. Superior techniques for disposal of highly radioactive waste (HLW). Prog. Nucl. Energy 59, 75-85.

Pusch, R., Yong, R.N., 2006. Microstructure of Smectite Clays and Engineering Performance. Taylor and Francis, London and New York.

Quirk, J.P., 1994. Interparticle forces: a basis for the interpretation of soil physical behavior. Adv. Agron. 53, 121-183.

Romero, E., 1999. Characterisation and Thermo-Hydro-Mechanical Behaviour of Unsaturated BoomClay: An Experimental Study. Universitat Politècnica de Catalunya, Barcelona (Available at http://www.tdx.cat/handle/10803/6224, last accessed September 2013).

Romero, E., Della Vecchia, G., Jommi, C., 2011. An insight into the water retention properties of compacted clayey soils. Geotechnique 61 (4), 313-328.

Romero, E., Gens, A., Lloret, A., 1999. Water permeability, water retention andmicrostructure of unsaturated compacted Boom clay. Eng. Geol. 54 (1-2), 117-127.

Romero, E., Simms, P.H., 2008. Microstructure investigation in unsaturated soils: a review with special attention to contribution ofmercury intrusion porosimetry and environmental scanning electron microscopy. Geotech. Geol. Eng. 26 (6), 705-727.

Swedish Nuclear Power Inspectorate, 2005. Engineered barrier system - long-term stability of buffer and backfill. Report from a Workshop in Lund, Sweden, November 1517, 2004. Synthesis and Extended Abstracts, SKI Report.

Tournassat, C., Appelo, C.A.J., 2011. Modelling approaches for anion-exclusion in compacted Na-bentonite. Geochim. Cosmochim. Acta 75 (13), 3698-3710.

US EPA, 1993. Quality assurance and quality control forwaste containment facilities. Technical Guidance Document. Risk Reduction Engineering Laboratory, Cincinnati, $\mathrm{OH}$. 
van Olphen, H., 1977. An Introduction to Clay Colloid Chemistry: For Clay Technologists, Geologists and Soil Scientists. John Wiley and Sons, New York.

Yong, R.N., 1999a. Introduction. Session I. Modeling of clay microstructure. Theme and concerns. Eng. Geol. 54 (1-2), 1.

Yong, R.N., 1999b. Overview of modeling of clay microstructure and interactions for prediction of waste isolation barrier performance. Eng. Geol. 54 (1-2), 83-91.

Zhang, F.S., Low, P.F., Roth, C.B., 1995. Effects on monovalent, exchangeable cations and electrolytes on the relation between swelling pressure and interlayer distance in montmorillonite. J. Colloid Interface Sci. 173 (1), 34-41. 